Josefine Theresia Koenigbauer*, Elisabeth Schalinski, Ute Jarchau, Ulrich Gauger, Katrin Brandt, Sandra Klaucke, Jens-Peter Scharf, Werner Rath and Lars Hellmeyer

\title{
Cervical ripening after cesarean section: a prospective dual center study comparing a mechanical osmotic dilator vs. prostaglandin E2
}

https://doi.org/10.1515/jpm-2021-0157

Received March 31, 2021; accepted July 15, 2021;

published online August 2, 2021

\section{Abstract}

Objectives: Worldwide, the overall cesarean section is rising. Trial of labor after cesarean (TOLAC) is an overall safe option with an immediate impact on neonatal and maternal short- and long-term health. Since the use of prostaglandins in cervical ripening is associated with an increased risk of uterine rupture, mechanical methods as balloon catheters or osmotic dilators have been suggested for cervical ripening prior to induction of labour. Here we are analyzing and comparing the VBAC rate, as well as maternal and fetal outcome in cervical ripening prior to TOLAC.

Methods: This prospective dual center study analyses maternal and neonatal outcomes of TOLAC in women with an unfavorable cervix requiring cervical ripening agent. The prospective application of an osmotic dilator (Dilapan-S, $\mathrm{n}=104$ ) was analysed in comparison to the retrospective application of off-label dinoprostone $(n=102)$.

Results: The overall fetal and neonatal outcome revealed no significant differences in both groups. Patients receiving cervical ripening with the osmotic dilator delivered vaginally/by ventouse in $52 \%$ of cases, compared to $53 \%$ when using dinoprostone $(\mathrm{p}=0.603)$. The interval between application to onset of labor was significantly higher

\footnotetext{
*Corresponding author: Josefine Theresia Koenigbauer, IBCLC, MD, Perinatal fellow, Department of Obstetrics and Gynecology, Vivantes Klinikum im Friedrichshain, Affiliate of Charité University, Landsberger Allee 49, 10249 Berlin, Germany, Phone: 0049130231442, E-mail: Josefine.Maier@gmail.com

Elisabeth Schalinski, Ute Jarchau and Lars Hellmeyer, Department of Obstetrics and Gynecology, Vivantes Klinikum im Friedrichshain, Affiliate of Charité University, Berlin, Germany

Ulrich Gauger, Institute of Medical Statistics, Berlin, Germany Katrin Brandt, Sandra Klaucke and Jens-Peter Scharf, Department of Obstetrics and Gynecology, Sana Klinikum Lichtenberg, Berlin, Germany

Werner Rath, Department of Obstetrics and Gynecology, University of Aachen, Aachen, Germany
}

in the osmotic dilator group (37.9 vs.20.7 h, $\mathrm{p}=<0.001$ ). However, time from onset of labor to delivery was similar in both groups ( 7.93 vs. $7.44 \mathrm{~h}, \mathrm{p}=0.758$ ). There was one case of uterine rupture in the dinoprostone group.

Conclusions: Our data shows that the application of the osmotic dilator leads to similar outcomes in VBAC rate and time from onset of labor to delivery as well as safety in both groups compared to off-label use dinoprostone. Cervical ripening using the mechanical dilator is a viable and effective option, without the risk of uterine hyperstimulation.

Keywords: cervical ripening; cesarean section (CS); cesarean section rate; osmotic dilator; repeat cesarean section (RCS); trial of labor after cesarean (TOLAC); unfavorable cervix; uterine scar; vaginal birth after cesarean (VBAC).

\section{Key message}

With the cesarean section rate rising, trial of labor appears as a viable option to counteract this trend. Overall, this analysis shows promising results on the efficiency and safety of the osmotic dilator in cervical ripening.

\section{Introduction}

Today, every third child in Germany is born via cesarean delivery. In 2018 the cesarean section (CS) rate in Germany was $29.1 \%$, compared to $15.3 \%$ in 1991 [1]. In the OECD countries (Organisation for Economic Co-operation and Development) $28.1 \%$ of deliveries were via cesarean section [2]. An increasing number of women have a uterine scar after CS and they require counseling regarding their subsequent delivery. These patients are at a slightly increased risk of complications during labor and delivery, such as uterine rupture [3, 4].

There are two options for women who have undergone one prior CS: either elective repeat cesarean (RCS) or trial of labor after cesarean (TOLAC), with both methods of delivery associated with certain risks [5-7]. It is of utmost importance to counsel a patient and weigh the pros and 
cons of both options when planning the delivery after caesarean. RCS is associated with increased maternal and fetal morbidity, such as blood loss, injury of internal organs, scarring/adhesions, and placental abnormalities (placenta accreta, increta, percreta, previa) as well as respiratory problems necessitating breathing assistance and oxygen supplementation $[5,8]$. TOLAC is associated with lower maternal/fetal morbidity and lower rates of complications in the following pregnancy $[9,10]$.

Statistically, 60-80\% will have a successful VBAC, depending on the individual situation [10-17]. Due to the rising number of cesarean deliveries, the promotion of VBAC is a good tool to decrease the CS rate on the population level. Women that are eligible for TOLAC with an unfavorable cervix and the necessity to induce labor pose a dilemma for the obstetrician: oxytocin as an induction agent is not promising in a Bishop Score $<6$ and the application of prostaglandins is not recommended on expert opinion level. According to the manufacturer prostaglandin (such as the prostaglandin E2/dinoprostone) or the double balloon catheter are contraindicated in this subgroup of patients. The potential risk of uterine rupture is as high as $2.24 \%$ in prostaglandin-induced labor vs. $0.52 \%$ in spontaneous labor in TOLAC [18]. The likelihood of uterine rupture when applying prostaglandin is especially elevated in those women with an unfavorable cervix $[19,20]$. Additionally, augmentation of labor in woman attributed to an increased risk of uterine rupture: $1.1 \%$ for oxytocin application, $0.9 \%$ for augmented labor and $0.4 \%$ for spontaneous labor [21]. Women with no prior vaginal delivery displayed a particularly increased likelihood of uterine rupture during TOLAC (1.5 vs. $0.8 \%, \mathrm{p}=0.02)$ [21]. The application of mechanical agents, such as balloon catheters or osmotic dilators, is a viable option: the Foley catheter and the balloon catheter appears to be a safe tool with a vaginal birth rate of $56.4 \%$ [22]. Other mechanical devices are osmotic dilators or laminaria tents, made from sterile sea-weed or synthetic hydrophilic materials [23]. Another osmotic dilator, called Dilapan- ${ }^{\circledR}$, is not contraindicated for the application in patients with a previous CS [24]. Here we are comparing a prospective observational group of patients with the retrospective application of prostaglandin E2 (dinoprostone) in safety and efficacy.

\section{Materials and methods}

This is a prospective comparative dual-center pilot study including 104 pregnant women attempting TOLAC that received cervical ripening with the osmotic dilator between 2016 and 2020 at the
"Vivantes Klinikum im Friedrichshain", a public tertiary care academic affiliate of Charité University, Berlin, Germany and a secondary perinatal center "Sana Klinikum Lichtenberg". This group was compared to a retrospective cohort of 102 patients that received dinoprostone between 2012 and 2007.

Included into this study were patients $\geq 18$ years, with a gestational age $\geq 37 / 0$, singleton pregnancies with cephalic presentation, one prior caesarean section with a low transverse uterine incision (operational technique was known), an unripe cervix (Bishop Score <6) and a medical indication for labor induction. No other conditions requiring primary RCS such as placenta praevia, vasa praevia, or severe diseases or indication for imminent delivery were apparent. Exclusion criteria were premature rupture of membranes, twins, or multiples.

We utilized a standardized protocol that implements cervical ripening by dinoprostone or the osmotic dilator as well as subsequent management of latent phase and active phase of labor (Figure 1). The osmotic dilator (Dilapan- $S^{\circledR}$ ) is a small rod made out of hydrophilic material. It is inserted into the cervical canal during a gynecological exam. Prior to insertion, a disinfectant appropriate for mucosal skin is applied (e.g. Octenisept ${ }^{\circledR}$ ). Up to five rods can be inserted during one session and left for $12 \mathrm{~h}$ in the cervical canal. Removing the osmotic dilator and inserting a new one was repeated individually up to three times. The mechanical device acts by absorbing fluids in the cervix, increasing the rod circumference and consequently ripening, shortening and effacing the cervix. After the insertion fetal heart rate is monitored via CTG for $30 \mathrm{~min}$. Patients of this subgroup are admitted to our labor ward and monitored regularly. If Bishop Score was $\geq 6$, labor induction with oxytocin was continued. Oxytocin was administered intravenously (6IE in $500 \mathrm{~mL}$ ) by an infusion pump, starting at $15 \mathrm{~mL} / \mathrm{h}(0.18 \mathrm{IE} / \mathrm{h})$. Oxytocin flow is increased every $30 \mathrm{~min}$, with the highest flow at $60 \mathrm{~mL} / \mathrm{h}$ in this subgroup of patients (0.72IE/h). Once oxytocin administration is initiated, amniotomy had to be performed within $2 \mathrm{~h}$.

Prostaglandin E2 (dinoprostone, Minprostin ${ }^{\circledR}$ ) was applied as a vaginal gel insert during an internal vaginal examination (1 and $2 \mathrm{mg}$, max. $3 \mathrm{mg}$ in $24 \mathrm{~h}$ ), initially commenced with $1 \mathrm{mg}$ and continued after $8 \mathrm{~h}$. The agent was used for a maximum of $48 \mathrm{~h}$ (a total amount of $6 \mathrm{mg}$ dinoprostone). Afterwards induction was continued with oxytocin, if the patient did not develop contractions.

Cervical status was assessed using the Bishop Score every time the osmotic dilator (every $12 \mathrm{~h}$ ) or dinoprostone (every 8-12 h) was exchanged/applied or if the patient developed contractions. The Bishop Score is a score on a scale from 0 to 10 including cervical length, effacement, consistency, as well as position and station of the fetal head [25]. The score was originally introduced by Bishop in 1964 and further modified in 1966 by Burnett [26].

Fetomaternal surveillance was conducted via fetal heart rate tracing (CTG) and maternal vital signs (heart rate, blood pressure, oxygen saturation). During cervical ripening with the osmotic dilator, fetomaternal surveillance was performed for $30 \mathrm{~min}$. Before the application of dinoprostone fetal well-being was confirmed for $15 \mathrm{~min}$, followed by $90 \mathrm{~min}$ after the application, and for another $60 \mathrm{~min} 4 \mathrm{~h}$ after the application.

The primary outcome was mode of delivery, while the secondary was the interval from admission to delivery. Prior to induction of labor, the Bishop Score is assessed.

Uterine rupture is a full thickness tear of the uterine wall including the uterine serosa, whereas uterine dehiscence is defined as gradual myometrial rupture with intact membranes/serosa [27]. 
The power analysis calculated group sample sizes of 92 and 92, achieving $80 \%$ power to detect non-inferiority using a one-sided, twosample t-test. Data was analysed using $R$ version 3.2.5. Among others Fisher's Exact Test for count data, Kruskal-Wallis rank sum test, Pearson's Chi-squared test were utilized.

\section{Ethical approval}

Prior to the analysis, we requested an ethics committee meeting and received approval from the Ethics Committee of the Ärztekammer, Berlin (September 20th, 2016; Eth-37/16).

\section{Results}

\section{Basic results}

Data was collected from 104 women receiving cervical ripening with the osmotic dilator presenting at our tertiary perinatal clinic (Vivantes Klinikum im Friedrichshain) and a secondary perinatal center (Sana Klinikum Lichtenberg) vs. 102 receiving off-label dinoprostone. There were no significant differences in the baseline characteristics (Table 1). All patients had one previous CS and were approximately $31.8-32.6$ years old and received cervical ripening at 41 weeks. The BMI was lightly overweight with 26.1-26.6. 76.9 vs. $77.4 \%$ (osmotic dilator, dinoprostone respectively) of women delivered one child prior via CS. Indication for induction of labor was for the most part for maternal reason (osmotic dilator $63 \%$ and dinoprostone $44 \%$; for example gestational diabetes, diabetes,

Table 1: Baseline characteristics.

\begin{tabular}{lrrr}
\hline & $\begin{array}{r}\text { Osmotic } \\
\text { dilator } \\
\mathbf{n = 1 0 4}\end{array}$ & Dinoprostone & $\begin{array}{r}\mathbf{p} \\
\text { overall }\end{array}$ \\
\hline Maternal age, years & $32.6(4.78)$ & $31.8(5.72)$ & 0.283 \\
BMI pre-pregnancy, $\mathrm{kg} / \mathrm{m}^{2}$ & $26.1(6.28)$ & $26.6(5.77)$ & 0.586 \\
Gravida & $3.02(1.34)$ & $3.18(1.33)$ & 0.400 \\
Para & $1.38(0.80)$ & $1.35(0.78)$ & 0.842 \\
No vaginal delivery & $80(77 \%)$ & $79(77.5 \%)$ & 0.767 \\
1 vaginal delivery & $13(12.5 \%)$ & $15(14.8 \%)$ & \\
$\geq 2$ vaginal deliveries & $11(10.5 \%)$ & $8(7.7 \%)$ & \\
Gestational weeks, days & $281(7.64)$ & $280(8.26)$ & 0.779 \\
upon delivery & & & \\
Indication for induction & & & 0.620 \\
Post-term pregnancy, $\mathrm{n}(\%)$ & $25(24 \%)$ & $29(28 \%)$ & \\
Maternal indication, $\mathrm{n}(\%)$ & $66(63 \%)$ & $45(44 \%)$ & \\
Fetal indication, $\mathrm{n}(\%)$ & $13(13 \%)$ & $28(28 \%)$ & \\
Initial Bishop score & $1.6(1.3)$ & $1.9(1.3)$ & 0.302 \\
\hline
\end{tabular}

Data are presented as mean $\pm S D$, or total number (percentage), BMI, body mass index. hypertension, preeclampsia/HELLP syndrome). Other indications were post-term pregnancy (osmotic dilator $24 \%$, dinoprostone $28 \%, 41 / 0$ gestational weeks) and fetal indication $(13 \%, 28 \%$, osmotic dilator, dinoprostone respectively; such as placental insufficiency, fetal growth restriction, oligohydramnios, polyhydramnions). All patients presented with an unfavorable cervix: the mean Bishop Score was 1.6 $( \pm 1.3)$ in the osmotic dilator group vs. $1.9( \pm 1.3)$ in the dinoprostone group.

\section{Time from application to birth}

The time period from application of the agent to onset of labor and time of birth was assessed (Table 2). Different time points were analysed. The time period from administration of the agent to onset of labor was significantly longer in the Dilapan-S ${ }^{\circledR}$ group compared to dinoprostone group with 37.9 vs. $20.7 \mathrm{~h}$ (mean, respectively, $\mathrm{p}=<0.001$ ). Time from onset of labor to delivery was similar in both groups with 7.9 and $7.4 \mathrm{~h}$ (mean, Dilapan- ${ }^{\circledR}$ group, dinoprostone group, respectively, $\mathrm{p}=0.758$ ). Therefore, the period from application of the cervical ripening agent to onset of labor was longer in those who received the osmotic dilator. However, time from onset of labor to delivery was comparable.

\section{Oxytocin augmentation/amniotomy}

For further induction/labor augmentation, oxytocin was administered (Table 3). Patients receiving cervical ripening with Dilapan- $S{ }^{\circledR}$ required labor augmentation significantly more frequently with oxytocin in $76 \%$ (79) in comparison to $43.1 \%$ (44) in the dinoprostone group $(\mathrm{p}=<0.001)$. The rates of spontaneous rupture of membranes or amniotomy were similar in both groups $(\mathrm{p}=0.580)$.

Table 2: Time from application to delivery.

\begin{tabular}{lrrr}
\hline & $\begin{array}{r}\text { Osmotic } \\
\text { dilator } \\
\mathbf{n = 1 0 4}\end{array}$ & Dinoprostone & $\begin{array}{r}\mathbf{p} \\
\text { overall }\end{array}$ \\
\hline $\begin{array}{l}\text { Time admission-onset/ } \\
\text { labor, hours }\end{array}$ & $37.9(23.3)$ & $20.7(17.8)$ & $<0.001$ \\
$\begin{array}{l}\text { Time admission-delivery, } \\
\text { hours }\end{array}$ & $46.5(24.9)$ & $31.8(24.0)$ & $<0.001$ \\
$\begin{array}{l}\text { Time onset labor-delivery, } \\
\text { hours }\end{array}$ & $7.93(10.4)$ & $7.44(9.58)$ & 0.758 \\
\hline
\end{tabular}

Data are presented as mean $( \pm S D)$. 
Table 3: Induction of labor with oxytocin and amniotomy.

\begin{tabular}{lrrr}
\hline & $\begin{array}{r}\text { Osmotic } \\
\text { dilator } \\
\mathbf{n = 1 0 4}\end{array}$ & Dinoprostone & $\begin{array}{r}\mathbf{p} \\
\text { overall }\end{array}$ \\
\hline $\begin{array}{l}\text { Labor augmentation with } \\
\text { oxytocin }\end{array}$ & $79(76.0 \%)$ & $44(43.1 \%)$ & $<0.001$ \\
$\begin{array}{l}\text { Amniotomy } \\
\begin{array}{l}\text { Spontaneous rupture of } \\
\text { membranes }\end{array}\end{array}$ & $56(53.8 \%)$ & $50(49.0 \%)$ & 0.580 \\
\hline
\end{tabular}

\section{Delivery mode}

Overall, results concerning delivery mode were similar ( $p=0.603$, Table 4). The cesarean section rate was $49.97 \%$ (44.2\% during labor and delivery and $5.77 \%$ on request of the mother) in the osmotic dilator group vs. $48.02 \%$ (44.1 and $3.92 \%$, respectively) in the dinoprostone group. $42.3 \%$ of patients delivered vaginally and $7.69 \%$ by ventouse. In those patients who required cervical ripening with dinoprostone $48 \%$ gave birth vaginally and $3.92 \%$ by ventouse.

\section{Maternal outcome: uterine rupture vs. dehiscence}

In our study cohort there was only one case of uterine rupture. A 32 year-old Gravida three Para one was induced with a total dosage of $3 \mathrm{mg}$ dinoprostone at 40 gestational weeks due to oligohydramnios. After onset of labor she delivered the baby quickly within $4 \mathrm{~h}$ vaginally with an umbilical artery $\mathrm{pH}$ of 6.86, base excess -18.6 and an Apgar of 6/10/10 (see case 2, fetal outcome). Directly postpartum she started bleeding. In the ultrasound there was free fluid and the suspicion of uterine rupture, therefore a laparotomy was performed confirming the suspicion. The patient was suffering a high blood loss of $10 \mathrm{~L}$ and received an emergency hysterectomy as well as postoperative intensive care. She was discharged from the

Table 4: Illustrating the delivery mode, data in total (percentage).

\begin{tabular}{lrrr}
\hline & $\begin{array}{r}\text { Osmotic dilator } \\
\mathbf{n = 1 0 4}\end{array}$ & $\begin{array}{r}\text { Dinoprostone } \\
\mathbf{n = 1 0 2}\end{array}$ & $\begin{array}{r}\mathbf{p} \\
\text { overall }\end{array}$ \\
\hline Mode of delivery & & & 0.603 \\
$\quad$ Spontanous vaginal & $44(42.3 \%)$ & $49(48.0 \%)$ & \\
Ventouse & $8(7.69 \%)$ & $4(3.92 \%)$ & \\
Cesarean section, & $6(5.77 \%)$ & $4(3.92 \%)$ & \\
primary, w/o labor & & & \\
Cesarean section, & $46(44.2 \%)$ & $45(44.1 \%)$ & \\
secondary & & & \\
\hline
\end{tabular}

hospital 10 days after the delivery. In the osmotic dilator group there were no cases of uterine rupture but three cases of uterine dehiscence that were diagnosed during the RCS. In the dinoprostone group there was one case of uterine dehiscence. These cases were diagnosed during RCS, fetal and maternal outcome was otherwise uneventful in these cases. Uterine dehiscence, in contrast to uterine rupture, is defined as an incomplete division, not penetrating all layers of the uterus. Usually, uterine dehiscence is an occult finding in an asymptomatic patient [28].

\section{Fetal outcome}

There were no significant differences concerning fetal outcome Tables 5 and 6 . Analysing the Apgar score after 1, 5 and $10 \mathrm{~min}$, fetal outcomes were very similar. No significant differences were found in average umbilical artery $\mathrm{pH}$ and Apgar scores. The lowest incidence of umbilical artery $\mathrm{pH}$ was found in the group of patients where dinoprostone was applied for cervical ripening, in this

Table 5: Apgar and pH outcomes, data as mean $( \pm S D)$.

\begin{tabular}{lrrr}
\hline & $\begin{array}{r}\text { Osmotic dilator } \\
\mathbf{n = 1 0 4}\end{array}$ & $\begin{array}{r}\text { Dinoprostone } \\
\mathbf{n = 1 0 2}\end{array}$ & $\begin{array}{r}\mathbf{p} \\
\text { overall }\end{array}$ \\
\hline Apgar_1min & $8.85(0.73)$ & $8.83(1.18)$ & 0.926 \\
Apgar_5min & $9.64(0.59)$ & $9.64(0.59)$ & 0.933 \\
Apgar_10min & $9.85(0.41)$ & $9.86(0.45)$ & 0.782 \\
NapH & $7.26(0.07)$ & $7.26(0.09)$ & 0.755 \\
NaBE & $-2.72(3.49)$ & $-4.13(3.86)$ & 0.014 \\
\hline
\end{tabular}

Table 6: Four cases of peripartum asphyxia with a pH of lower than 7.10

\begin{tabular}{llll}
\hline$<7.10$ & & Osmotic dilator & Dinoprostone \\
\hline Case 1 & & $7.07 \mathrm{BE}-7.4$ & \\
& Mode of delivery & Vaginally & \\
& Apgar & $6 / 8 / 10$ & \\
& Birth weight & $4110 \mathrm{~g}$ & \\
Case 2 & & & $6.86 \mathrm{BE}-18.6$ \\
& Mode of delivery & & Vaginally \\
& Apgar & $6 / 10 / 10$ \\
& Birth weight & $3470 \mathrm{~g}$ \\
Case 3 & & $7.06 \mathrm{BE}-10.6$ \\
& Mode of delivery & & Vaginally \\
& Apgar & $9 / 10 / 10$ \\
& Birth weight & $3200 \mathrm{~g}$ \\
Case 4 & & $7.08 \mathrm{BE}-13$ \\
& Mode of delivery & & Ventouse \\
& Apgar & $6 / 9 / 10$ \\
& Birth weight & $3540 \mathrm{~g}$ \\
\hline
\end{tabular}




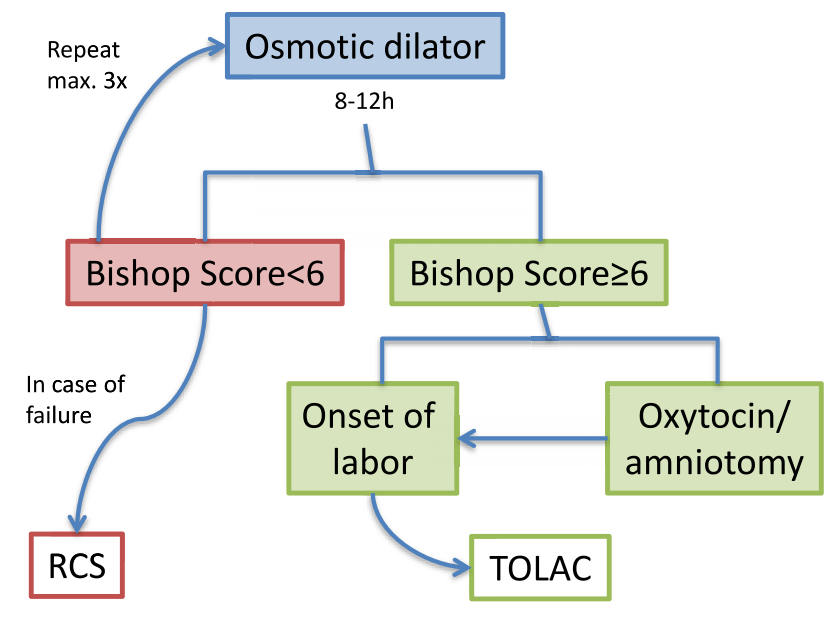

Figure 1: Flow-chart depicting the application of the osmotic dilator and subsequent steps depending on Bishop Score.

case due to uterine hyperstimulation $(\mathrm{pH} 6.86$, base excess -18.6, vaginal delivery, Apgar 6/10/10). Overall, both groups had a similar proportion of umbilical artery pH lower than 7.20 (20.2 vs. $21.6 \%$, Dilapan- $S^{\circledR}$ group, dinoprostone group, respectively).

\section{Discussion}

With the cesarean section rate rising, trial of labor appears as a viable option to counteract this trend. Vaginal birth after cesarean can decrease the rates of short-term and long-term maternal and fetal complications [10]. TOLAC is a good option for influencing the overall rising CS rate, with a success rate of $80-60 \%$ leading to VBAC $[16,29,30]$. If induction of labor is required, the obstetrician's choice is limited as most pharmacological/mechanical agents prescribed (Prostaglandin, double balloon catheter) are not officially licensed for the usage in this particular group of patients. Moreover evidence on appropriate and safe options is very limited [31]. Legal consequences can be very harsh and therefore influence the physician in their decision in favor of the seemingly safer option, the RCS. This is why we are studying the application of an in-label device in patients with one prior cesarean section. As there is no comparative in-label agent available in this subgroup of patients, we had to compare the application with off-label prostaglandin from the past.

\section{Principal findings}

In this comparative study we were analysing 104 patients that received cervical ripening with the osmotic dilator to
102 patients that received prostaglandins (dinoprostone). The power analysis that was previously performed calculated group sample sizes of 92 and 92, achieving $80 \%$ power to detect non-inferiority. The two groups appear to be comparable with no significant differences between the two populations.

\section{Mode of delivery}

The overall success rate of VBAC is described as $60-80 \%$, whereas women presenting with spontaneous onset of labor have the highest success rate [10,13-16]. Recent studies have shown a prediction model to assess the success rate of vaginal delivery after cesarean using head circumference, subpubic angle and cervical length [32]. In addition, the indication for the CS prior to the current delivery has an impact on the success rate of TOLAC (e.g. breech, failure to progress in first or second stage of labor) [33]. Unfortunately, due to the small sample size, the indication for the prior CS was not extensively evaluated. This should be assessed in larger studies in the future.

Evidence concerning cervical ripening in women with one previous CS is limited. The American College of Obstetricians and Gynecologists (ACOG), the Royal College of Obstetricians and Gynecologists (RCOG), and the French College of Gynecologists and Obstetricians (CNGOF) suggest in their bulletins the use of mechanical ripening agents, as there is no "negative" evidence associated to them. Furthermore, they do not recommend the application of PGE2 in this subgroup of patients [7, 10, 34]. Evidence on cervical ripening with the double-balloon catheter in TOLAC demonstrated a vaginal birth rate of $43.8-56.4 \%[35,36]$. In our study the VBAC rate was similar in both groups with 49.9 vs. $51.9 \%$ resembling the results from the double balloon catheter $(p=0.602$, osmotic dilator, dinoprostone, respectively). Notably the patients included into this study were at a gestational age of 41 weeks on average and had a very low Bishop Score of 1.5 (osmotic dilator group). Research has shown that post-term pregnancy in TOLAC has a decreased chance of VBAC [10].

Overall, when counseling a patient planning TOLAC and who presents with an indication for cervical ripening and labor induction, we can inform them that they have a $50 \%$ success rate on average.

\section{Time period}

The time period from first insertion or application to onset of labor was significantly longer in the osmotic dilator 
group ( $p=0.005)$, which can be explained through the different mechanism of action of both agents. Interestingly, the time period was similar from onset of labor to delivery in both groups $(\mathrm{p}=0.7474)$. Cromi et al. observed a similar pattern with their study on the transcervical Foley vs. prostaglandins for cervical ripening: the mechanical device had a lower rate of vaginal birth within $24 \mathrm{~h}$ compared to prostaglandins, but the same overall chance of vaginal birth [37]. A longer interval from cervical ripening to active phase of labor has been described in patients with a previous CS when comparing to nulliparous women [38]. Additionally, a mechanical agent that works slower and therefore prevents uterine hyperstimulation decreasing the risk of uterine rupture is an aspect that is deliberately desired in TOLAC.

\section{Oxytocin and amniotomy}

A current meta-analysis revealed a correlation between oxytocin use in TOLAC and risk of uterine rupture [16]. The uterine rupture risk is estimated to be $1 \%$ in oxytocin and to be dose-dependent [7]. Oxytocin ought not to be routinely used in TOLAC and if it is, should be maintained at the lowest concentration to sustain contractions. In comparison, the application of vaginal prostaglandins increases the uterine rupture risk by about $2 \%$, therefore the usage of prostaglandin in induction of labor in this subgroup is not generally recommended and should be considered carefully [7]. In our analysis, we found higher rates of oxytocin application and/or amniotomy in the group of the osmotic dilator. This can be explained through the mechanical mode of action of the osmotic dilator in comparison to the vaginal application of dinoprostone that acts there continuously. In our osmotic dilator protocol, we recommend performing artificial rupture of membranes after a maximum of $2 \mathrm{~h}$ of oxytocin administration. Research shows that after cervical ripening, routine early amniotomy shortens the interval from induction to delivery and does not increase the risk of secondary RCS [39].

\section{Safety}

Recent studies showed that uterine rupture occurs at a frequency of $0.2 \%$ in all patients attempting vaginal birth after having one previous cesarean section [40, 41]. The risk of uterine rupture is dependent on different aspects: the type of uterine suture (single stitches vs. continuous stitching), excessive diathermy, wound healing, and other conditions [27]. There is evidence that induction of labor and cervical ripening impose different risks on uterine rupture and consequently on maternal and fetal health. The risk of uterine rupture appears to be lowest with oxytocin but dependent on dosage, the risk increasing with the application of prostaglandins $[7,10,16]$. There is little evidence on mechanical devices. Studies with the double balloon catheter revealed a very low uterine rupture rate of $1.2 \%(18 / 1447)$ [36]. In this study we observed one uterine rupture with a substantial maternal and fetal morbidity (fetal asphyxia and emergency hysterectomy) in the dinoprostone group. There were three cases of uterine dehiscence in the osmotic dilator group and one case in the dinoprostone group. These cases were diagnosed by chance during the RCS und both maternal and fetal outcome were uneventful. Due to the small sample size ( $n=104$ and 102) further studies with larger cohorts need to be performed in this critical safety aspect. Additionally, the aspect of uterine hyperstimulation should be further analysed in larger cohorts. We suspect a lower incidence of uterine hyperstimulation in the osmotic dilator group because of its slower way of acting, e.g. longer interval from insertion to onset of labor in this group.

Fetal outcome was comparable in both groups with no significant differences.

\section{Critical assessment of this study and future outlook}

Here we are prospectively comparing the application of the osmotic dilator to the off-label and currently not recommended usage of dinoprostone in patients with one prior CS (historic group). We were able to show that cervical ripening in this subgroup with a low Bishop Score and therefore a higher risk of secondary RCS and uterine rupture had a success rate of vaginal delivery in 49.9 vs. $51.9 \%$ (osmotic dilator, dinoprostone, respectively). This data is analogous to the evidence in literature with a vaginal birth rate of $43.8-56.4 \%$ and our own previous publications [24, $35,36]$. Still, the number of women included into this study is too small to facilitate a more comprehensive analysis.

Overall, this comparative analysis shows promising results on the efficiency and safety of the osmotic dilator in cervical ripening before TOLAC and underlines the current recommendations from the ACOG, RCOG and CNGOF. The results are limited by the fact that the control group consists of a retrospective series. 


\section{Conclusions}

To date there is no published study with a randomized setting analysing the application of the osmotic dilator in women with one previous $\mathrm{CS}$. This study concludes that the osmotic dilator is a viable option for cervical ripening in women who had a previous cesarean section. It is as effective in mode of delivery and actual time from onset of labor to delivery as prostaglandins.

In women with one previous CS we want to be careful with the administration of drugs that are known to implement a higher risk of uterine hyperstimulation and pathological fetal heart rate tracing. With the osmotic dilator and its mechanical mode of action it is understandable that it acts slower than prostaglandins and has a higher need for well-controllable titration of Oxytocin and amniotomy.

In the future we would like to initiate an international randomized controlled study on the application of the osmotic dilator vs balloon catheter. We hope that eventually more women are provided with the opportunity of VBAC and that the overall cesarean section rate can be lowered.

Additionally, the osmotic dilator appears to be a safe and viable option in outpatient cervical ripening and could therefore reduce hospital stays and socioeconomic costs. Furthermore, in the face of a worldwide pandemic, outpatient cervical ripening in a low risk cohort leads to less individual contacts and a smaller likelihood to get infected or spread SARS-CoV-2.

Research funding: None declared.

Author contributions: Koenigbauer, Josefine Theresia MD, contributed to the study development, patient recruitment, statistical analysis, writing of the article. Schalinski, Elisabeth MD, contributed to the study development, patient recruitment. Jarchau, Ute MD, contributed to patient recruitment. Gauger, Ulrich $\mathrm{PhD}$, contributed to study development, statistical analysis. Brandt, Katrin, contributed to patient recruitment. Klaucke, Sandra MD, contributed to patient recruitment. Scharf, Jens-Peter MD, contributed to patient recruitment. Rath, Werner Prof MD, the study development, writing of the article. Hellmeyer, Lars Prof MD, the study development, patient recruitment, statistical analysis, writing of the article. All authors have accepted responsibility for the entire content of this manuscript and approved its submission.

Competing interests: Koenigbauer, Josefine Theresia MD, states to have no potential conflicts of interests. There are no financial and personal relationships that could be viewed as presenting a potential conflict of interest (such as patent or stock ownership, consultancies, speaker's fees, personal, political, intellectual or religious interests). Schalinski, Elisabeth MD, states to have no potential conflicts of interests. There are no financial and personal relationships that could be viewed as presenting a potential conflict of interest (such as patent or stock ownership, consultancies, speaker's fees, personal, political, intellectual or religious interests). Jarchau, Ute MD, states to have no potential conflicts of interests. There are no financial and personal relationships that could be viewed as presenting a potential conflict of interest (such as patent or stock ownership, consultancies, speaker's fees, personal, political, intellectual or religious interests). Gauger, Ulrich PhD, states to have no potential conflicts of interests. There are no financial and personal relationships that could be viewed as presenting a potential conflict of interest (such as patent or stock ownership, consultancies, speaker's fees, personal, political, intellectual or religi ous interests). Brandt, Katrin, states to have no poten tial conflicts of interests. There are no financial and personal relationships that could be viewed as presenting a potential conflict of interest (such as patent or stock ownership, consultancies, speaker's fees, personal, political, intellectual or religious interests). Klaucke, Sandra MD, states to have no potential conflicts of interests. There are no financial and personal relationships that could be viewed as presenting a potential conflict of interest (such as patent or stock ownership, consultancies, speaker's fees, personal, political, intellectual or religious interests). Scharf, JensPeter MD, states to have no potential conflicts of interests. There are no financial and personal relationships that could be viewed as presenting a potential conflict of interest (such as patent or stock ownership, consultancies, speaker's fees, personal, political, intellectual or religious interests). Rath, Werner Prof MD, states to have no potential conflicts of interests. There are no financial and personal relationships that could be viewed as presenting a potential conflict of interest (such as patent or stock ownership, consultancies, speaker's fees, personal, political, intellectual or religious interests). Hellmeyer, Lars Prof MD, states to have no potential conflicts of interests. There are no financial and personal relationships that could be viewed as presenting a potential conflict of interest (such as patent or stock ownership, consultancies, speaker's fees, personal, political, intellectual or religious interests).

Informed consent: Informed consent was obtained from all individuals included in this study.

Ethical approval: Prior to the analysis, we requested an ethics committee meeting and received approval from the Ethics Committee of the Ärztekammer, Berlin (September 20th, 2016; Eth-37/16). 


\section{References}

1. Federal Statistical Office Germany: hospital deliveries in Germany. 2020.

2. Health at a Glance 2019. OECD; 2019: 200-1 pp.

3. Marshall NE, Fu R, Guise J-M. Impact of multiple cesarean deliveries on maternal morbidity: a systematic review. Am J Obstet Gynecol 2011 Jun 15;205:262.e1-8. [Epub ahead of print].

4. Gregory K, Jackson S, Korst L, Fridman M. Cesarean versus vaginal delivery: whose risks? Whose benefits? Am J Perinatol 2012 Aug 10;29:7-18. [Epub ahead of print].

5. Dodd JM, Crowther CA, Grivell RM, Deussen AR. Elective repeat caesarean section versus induction of labour for women with a previous caesarean birth. Cochrane Database Syst Rev 2017;7. https://doi.org/10.1002/14651858.cd004906.pub5.

6. Lehmann S, Baghestan E, Børdahl PE, Irgens LM, Rasmussen S. Low risk pregnancies after a cesarean section: determinants of trial of labor and its failure. PloS One 2020;15:e0226894.

7. Sentilhes L, Vayssière C, Beucher G, Deneux-Tharaux C, Deruelle $P$, Diemunsch $P$, et al. Delivery for women with a previous cesarean: guidelines for clinical practice from the French College of Gynecologists and Obstetricians (CNGOF). Eur J Obstet Gynecol Reprod Biol 2013 Jun 28;170:25-32. [Epub ahead of print].

8. Dodd JA, Crowther C. Vaginal birth after Caesarean section: a survey of practice in Australia and New Zealand. Aust New Zeal J Obstet Gynaecol 2003;43:226-31.

9. Practice Bulletin No. 115. Vaginal birth after previous cesarean delivery. Obstet Gynecol 2010;116:450-63.

10. ACOG practice bulletin No. 205. Obstet Gynecol. 2019;133: e110-27.

11. Gobillot S, Ghenassia A, Coston AL, Gillois P, Equy V, Michy T, et al. Obstetric outcomes associated with induction of labour after caesarean section. J Gynecol Obstet Hum Reprod 2018;47: 539-43.

12. Thapsamuthdechakorn A, Sekararithi R, Tongsong T. Factors associated with successful trial of labor after cesarean section: a retrospective cohort study. J Pregnancy 2018;2018:6140982.

13. Delpero E, Tannenbaum E, Thomas J. Labour management in trial of labour after C-section (TOLAC): a gap analysis and quality improvement initiative. J Obstet Gynaecol Can 2020;S1701-2163: 30975-0. [Epub ahead of print].

14. Fishel Bartal M, Sibai BM, Ilan H, Fried M, Rahav R, Alexandroni H, et al. Trial of labor after cesarean (TOLAC) in women with premature rupture of membranes. J Matern Neonatal Med 2020 Jan 17;33:2976-82. [Epub ahead of print].

15. Li Y-X, Bai Z, Long D-J, Wang H-B, Wu Y-F, Reilly KH, et al. Predicting the success of vaginal birth after caesarean delivery: $\mathrm{a}$ retrospective cohort study in China. BMJ Open 2019;9:e027807.

16. Zhang H, Liu H, Luo S, Gu W. Oxytocin use in trial of labor after cesarean and its relationship with risk of uterine rupture in women with one previous cesarean section: a meta-analysis of observational studies. BMC Pregnancy Childbirth 2021;21:11.

17. Ten Eikelder MLG, Oude Rengerink K, Jozwiak M, de Leeuw JW, de Graaf IM, van Pampus MG, et al. Induction of labour at term with oral misoprostol versus a Foley catheter (PROBAAT-II): a multicentre randomised controlled non-inferiority trial. Lancet 2016 Feb 3;387:1619-28. [Epub ahead of print].

18. Lydon-Rochelle M, Holt VL, Easterling TR, Martin DP. Risk of uterine rupture during labor among women with a prior cesarean delivery. N Engl J Med 2001;345. https://doi.org/10.1056/ NEJM200107053450101.

19. Harper LM, Cahill AG, Boslaugh S, Odibo AO, Stamilio DM, Roehl $K A$, et al. Association of induction of labor and uterine rupture in women attempting vaginal birth after cesarean: a survival analysis. Am J Obstet Gynecol 2012;206:3-8.

20. Macones GA, Peipert J, Nelson DB, Odibo A, Stevens EJ, Stamilio $\mathrm{DM}$, et al. Maternal complications with vaginal birth after cesarean delivery: a multicenter study. Am J Obstet Gynecol 2005; 193:1656-62.

21. Landon MB, Hauth JC, Leveno KJ, Spong CY, Leindecker S, Varner MW, et al. Maternal and perinatal outcomes associated with a trial of labor after prior cesarean delivery. N Engl J Med 2004 Dec 14;351:2581-9. [Epub ahead of print].

22. Rath W, Kehl S. The renaissance of transcervical balloon catheters for cervical ripening and labour induction. Geburtshilfe Frauenheilkd 2015;75:1130-9.

23. de Vaan MD, Ten Eikelder ML, Jozwiak M, Palmer KR, Davies-Tuck $\mathrm{M}$, Bloemenkamp KW, et al. Mechanical methods for induction of labour. Cochrane Database Syst Rev 2019;10:CD001233. [Epub ahead of print].

24. Maier JT, Metz M, Watermann N, Li L, Schalinski E, Gauger U, et al. Induction of labor in patients with an unfavorable cervix after a cesarean using an osmotic dilator versus vaginal prostaglandin. J Perinat Med 2018;46:299-307.

25. Kolkman D, Verhoeven C, Brinkhorst S, van der Post J, Pajkrt E, Opmeer B, et al. The Bishop score as a predictor of labor induction success: a systematic review. Am J Perinatol 2013 Jan 2; 30:625-30. [Epub ahead of print].

26. Teixeira C, Lunet N, Rodrigues T, Barros H. The Bishop Score as a determinant of labour induction success: a systematic review and meta-analysis. Arch Gynecol Obstet 2012 May 1;286:739-53. [Epub ahead of print].

27. Tanos V, Toney ZA. Uterine scar rupture - prediction, prevention, diagnosis, and management. Best Pract Res Clin Obstet Gynaecol 2019;59:115-31.

28. Guiliano M, Closset E, Therby D, LeGoueff F, Deruelle P, Subtil D. Signs, symptoms and complications of complete and partial uterine ruptures during pregnancy and delivery. Eur J Obstet Gynecol Reprod Biol 2014 May 22;179:130-4. [Epub ahead of print].

29. Fagerberg MC, Maršál K, Källén K. Predicting the chance of vaginal delivery after one cesarean section: validation and elaboration of a published prediction model. Eur J Obstet Gynecol Reprod Biol 2015 Mar 10;188:88-94. [Epub ahead of print].

30. Wilson-Leedy JG, DiSilvestro AJ, Repke JT, Pauli JM. Reduction in the cesarean delivery rate after obstetric care consensus guideline implementation. Obstet Gynecol 2016; 128:145-52.

31. West HM, Jozwiak M, Dodd JM. Methods of term labour induction for women with a previous caesarean section. Cochrane Database Syst Rev 2017;6:CD009792.

32. Rizzo G, Bitsadze V, Khizroeva J, Mappa I, Makatsariya A, Liberati $M$, et al. Role of ante-partum ultrasound in predicting vaginal birth after cesarean section: a prospective cohort study. Eur J Obstet Gynecol Reprod Biol 2021 Nov 21;256:385-90. [Epub ahead of print].

33. Grobman WA, Lai Y, Landon MB, Spong CY, Leveno KJ, Rouse DJ, et al. Development of a Nomogram for prediction of vaginal birth after cesarean delivery. Obstet Gynecol 2007;109:806-12. 
34. RCOG. Birth After Previous Cesarean Birth Green-top Guideline No. 45; 2015. Available from: https://www.rcog.org.uk/en/guidelinesresearch-services/guidelines/gtg45/ [Accessed 17 Jan 2021].

35. Vital M, Grange J, Le Thuaut A, Dimet J, Ducarme G. Predictive factors for successful cervical ripening using a double-balloon catheter after previous cesarean delivery. Int J Gynecol Obstet 2018 Jun 29;142:288-94. [Epub ahead of print].

36. Kehl S, Weiss C, Rath W. Balloon catheters for induction of labor at term after previous cesarean section: a systematic review. Eur ] Obstet Gynecol Reprod Biol 2016 Aug 3;204:44-50. [Epub ahead of print].

37. Cromi A, Ghezzi F, Agosti M, Serati M, Uccella S, Arlant V, et al. Is transcervical Foley catheter actually slower than prostaglandins in ripening the cervix? A randomized study. Am J Obstet Gynecol 2011 Jan 26;204:338.e1-7. [Epub ahead of print].

38. Grantz KL, Gonzalez-Quintero V, Troendle J, Reddy UM, Hinkle SN, Kominiarek MA, et al. Labor patterns in women attempting vaginal birth after cesarean with normal neonatal outcomes. Am J Obstet Gynecol 2015 Apr 30;213:226.e1-6. [Epub ahead of print].

39. De Vivo V, Carbone L, Saccone G, Magoga G, De Vivo G, Locci M, et al. Early amniotomy after cervical ripening for induction of labor: a systematic review and meta-analysis of randomized controlled trials. Am J Obstet Gynecol 2020 Aug 6;222:320-9. [Epub ahead of print].

40. Uterine rupture is rarer than previously thought | NPEU [Internet]. Available from: https://www.npeu.ox.ac.uk/news/ 31-uterine-rupture-is-rarer-than-previously-thought [Accessed 16 Jan 2021].

41. Vandenberghe G, Bloemenkamp K, Berlage S, Colmorn L, Deneux-Tharaux C, Gissler M, et al. The International Network of Obstetric Survey Systems study of uterine rupture: a descriptive multi-country population-based study. BJOG An Int J Obstet Gynaecol 2019 Jun 12;126:370-81. [Epub ahead of print]. 